\title{
Show them how it's really done
}

\section{The public's appetite for science will not be whetted by a diet of dry facts.}

\section{Nancy J. Rothwell}

$\mathrm{P}$ eter Medawar, Nobel laureate, was remarkably perceptive: "the ideas of the educated lay public on the nature of scientific enquiry and the intellectual character of those who carry it out are in a state of dignified, yet utter, confusion. Most of these misconceptions are harmless enough, but some are mischievous, and all help to estrange the sciences from the humanities and the so called 'pure' sciences from the applied," (Encounter, August 1965). Medawar had put his finger on a major issue - and one that is probably even more relevant today than it was 35 years ago.

Science has never had a higher public profile. The public understanding of science is hotly debated in most of the developed world, as governments, educationalists and scientists themselves realize the need to explain what scientists do and the benefits that accrue from their (often expensive) labours. But much of this misses Medawar's key points. Knowing scientific facts does not automatically translate into an understanding of science. Sadly, few outside the profession know what scientists actually do, or what drives them to do it. Indeed, most know little of what science is really about.

The communication of science to society is not new, nor is it an easy task. It is almost 200 years since Albemarle Street in London, home of the Royal Institution, was designated the first one-way thoroughfare- - because of the crowds that flocked to see Humphrey
Davy's lectures. The remarkable popularity of these lectures and those of his successor, Michael Faraday, was probably because they used fascinating demonstrations, rather than simply telling people what to believe. Davy and Faraday were also great storytellers - and stories, of course, are the key to captivating an audience.

Some of the best accounts of science tell of people as much as facts, of personal circumstances, battles with dogma and establishment, luck, despair, breakthroughs, and even a few scandals. The popularity of The Double Helix owed as much to James Watson's juicy descriptions of personal conflicts as to the magnitude of the scientific discovery. John Gribbin brought the complexities of defining the Hubble constant to a wide audience in his book The Birth of Time: How We Measured the Universe, and the story of Faraday's humble beginnings as the son of a Yorkshire smith has fascinated and inspired many.

Such accounts not only explain the complexities of science, but also give an insight into what science and scientists are really about. Today, the teaching of science in schools, and its presentation to the public, focuses heavily on facts, leaving little room for enquiry or imagination. This does not reflect the reality of research, and ignores the most exciting part - the process of discovery itself. Research is like a detective story, in which knowing 'whodunnit', and how, is not enough - it's the process of deduction that really appeals.

We should not underestimate the public's

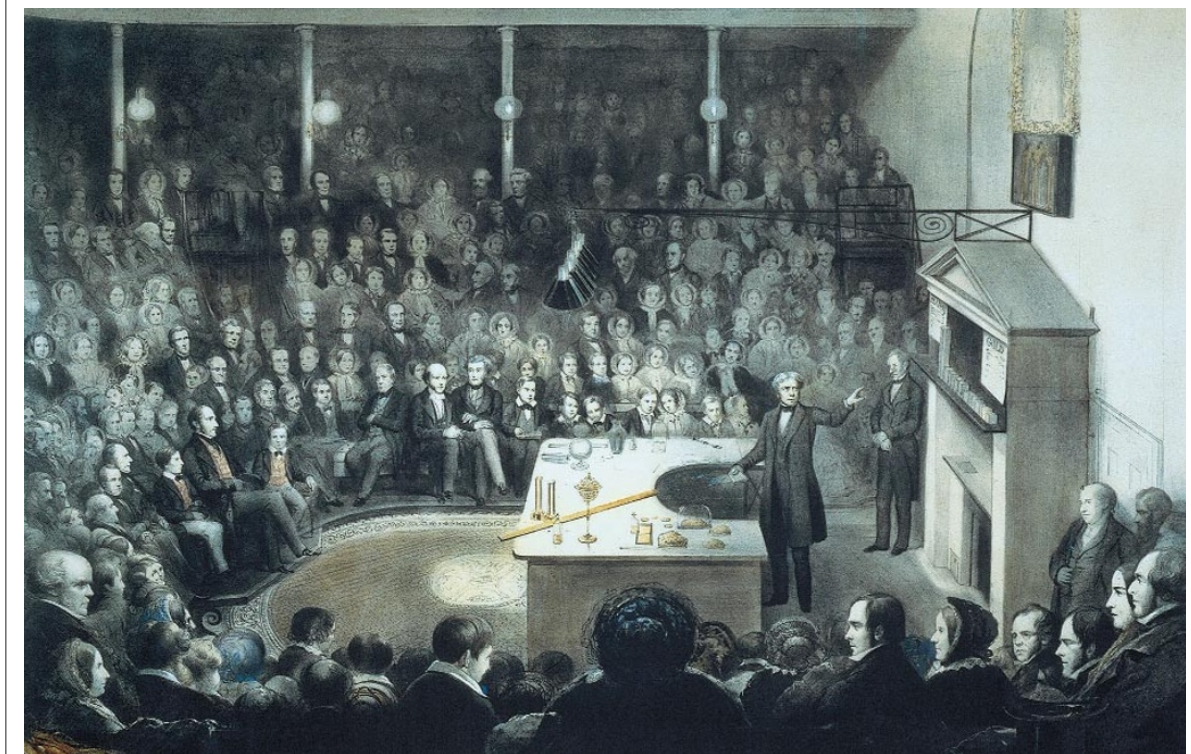

Packing them in: Michael Faraday, with his storytelling and demonstrations, was a born showman. interest in science, nor its ability to comprehend complex issues. Fascination with the physical and natural world is not the exclusive domain of professional scientists, nor is it dependent on a higher degree or scientific training. But the playful yet influential portrayal by the popular media of the nutty professor or mad scientist does little to benefit science. Scientists themselves tend to promote logic, analysis and rigorous experimentation as the major (or even only) bases of research and discovery, when in reality they also rely on intuition, imagination and inventiveness, much of which does not follow the general view of common sense.

Medawar's most important point is one of the hardest to address - the growing divide between sciences and humanities, and between curiosity-driven and applied research. In presenting our work and discoveries to the public, we strive to justify their importance and cost by their benefits to humans, animals or the environment. And indeed, most people are supportive of research with obvious benefits, although this is like an investor telling his or her broker to buy shares - but only those that will increase in value.

To engage the public in what research is really about - the pursuit of knowledge - is a challenge, given science's growing complexity and rapid advance. Most advances have flowed not from a desire to improve society, but from natural human curiosity although the benefits, sometimes not realized for many decades, have been considerable. The biologist J. B. S. Haldane believed that no one could have predicted that measuring the length of mercury columns could lead to an understanding of thunderstorms and fever, and the statistician Karl Pearson thought that Heinrich Hertz's discovery of electromagnetic forces had no useful application. Marconi proved him wrong.

Even Ernest Rutherford saw atomic physics as "useless" - at least initially. In the past decade, studies of the soil nematode Caenorhabditis elegans have revolutionized our understanding of cell death and survival, yet the worm biologists were probably not driven by the desire to understand or treat cancer and degenerative diseases, but rather by a fascinating biological problem. Discovery is the real pleasure of science. To give the last word to Medawar: "Pure science requires no justification outside itself, and its usefulness has no bearing on its valuation." Nancy J. Rothwell is in the School of Biological Sciences, Stopford Building, University of Manchester, Manchester M13 9PT, UK. 